\title{
Mercedes-Benz F015 - autonome Mobilität der Zukunft
}

Sylvain Wehnert, Daimler AG

Vortrag lag zu Redaktionsschluss nicht vor.

Vielen Dank für Ihr Verständnis. 